\title{
Spatial landslide susceptibility mapping using integrating an adaptive neuro-fuzzy inference system (ANFIS) with two multi-criteria decision- making approaches
}

\section{Sina Paryani}

Islamic Azad University Science and Research Branch

Aminreza Neshat ( $\nabla$ neshat.aminreza@srbiau.ac.ir)

Islamic Azad University Science and Research Branch https://orcid.org/0000-0001-9557-3570

Biswajeet Pradhan

Islamic Azad University Science and Research Branch

\section{Research Article}

Keywords: landslide susceptibility, machine learning, GIS, ANFIS, SWARA, BWM

Posted Date: March 10th, 2021

DOl: https://doi.org/10.21203/rs.3.rs-299575/v1

License: (c) (1) This work is licensed under a Creative Commons Attribution 4.0 International License. Read Full License

Version of Record: A version of this preprint was published at Theoretical and Applied Climatology on August 16th, 2021. See the published version at https://doi.org/10.1007/s00704-021-03695-w. 
1 Spatial landslide susceptibility mapping using integrating an adaptive neuro-fuzzy 2 inference system (ANFIS) with two multi-criteria decision-making approaches

3 Sina Paryani ${ }^{\mathrm{a}}$, Aminreza Neshat ${ }^{\mathrm{a} *}$, Biswajeet Pradhan ${ }^{\mathrm{b}, \mathrm{c}}$

4

5 a Department of GIS/RS, Faculty of Natural Resources and Environment, Science and Research Branch, Islamic 6 Azad University, Tehran, Iran

${ }^{\mathrm{b}}$ Centre for Advanced Modelling and Geospatial Information Systems (CAMGIS), Faculty of Engineering and IT, University of Technology Sydney, New South Wales, Australia

10

${ }^{\mathrm{c}}$ Department of Energy and Mineral Resources Engineering, Choongmu-gwan, Sejong University, 209,

12 Neungdong-roGwangin-gu, Seoul 05006, Korea

13

Correspondence:

Assistant Prof. Dr. Aminreza Neshat

Phone: +982122112144

Cell phone: $+989121946646,+17783166646$

Fax: +982122111603

Department of GIS/RS, Faculty of Natural Resources and Environment, Science and

Research Branch, Islamic Azad University, Tehran, Iran

Email: neshat.aminreza@gmail.com, neshat.aminreza@srbiau.ac.ir

16 ORCID: https://orcid.org/0000-0001-9557-3570

17 


\section{Abstract}

Landslide is a type of slope processes causing a plethora of economic damage and loss of lives worldwide every year. This study aimed to analyze spatial landslide susceptibility mapping in the Khalkhal-Tarom Basin by integrating an adaptive neuro-fuzzy inference system (ANFIS) with two multi-criteria decision-making approaches, i.e. the stepwise weight assessment ratio analysis (SWARA) and the new best-worst method (BWM) techniques. For this purpose, the first step was to prepare a landslide inventory map, which were then divided randomly by the ratio of 30/70 for model training and validation. Thirteen conditioning factors were used as slope angle, slope aspect, altitude, topographic wetness index (TWI), plan curvature, profile curvature, distance to roads, distance to streams, distance to faults, lithology, land use, rainfall and normalized difference vegetation index (NDVI). After the database was created, the BWM and the SWARA methods were utilized to determine the relationships between the sub-criteria and landslides. Finally, landslide susceptibility maps were generated by implementing ANFISSWARA and ANFIS-BWM hybrid models, and the ROC curve was employed to appraise the predictive accuracy of each model. The results showed that the areas under curves (AUC) for the ANFIS-SWARA and ANFIS-BWM models were $73.6 \%$ and $75 \%$ respectively, and that the novel BWM yielded more realistic relationships between effective factors and the landslides. As a result, it was more efficient in training the ANFIS. Evidently, the generated landslide susceptibility maps (LSMs) can be very efficient in managing land use and preventing the damage caused by the landslide phenomenon.

Keywords: landslide susceptibility; machine learning; GIS; ANFIS; SWARA; BWM

\section{Introduction}

46 Causing great losses of lives and properties, landslides are dangerous processes that occur repeatedly in mountainous and hilly areas worldwide, (Juliev et al. 2019; Gutiérrez et al. 2015). This mass movement occurs whenever the loading of an earth material exceeds its shear strength (Lin et al. 2017). Although this geological phenomenon is often triggered by earthquakes and heavy rainfalls, the expansion of anthropogenic activities in susceptible areas has always played an important factor in its occurrence (Baena et al. 2019) Despite the 
increased human knowledge regarding landslide occurrence and factors controlling this

53 phenomenon, it is believed that the damage caused by landslides will increase due to deforestation, climate change and urban development (Pham and Prakash 2018). Therefore, it is essential to acquire accurate and realistic information about the spatial distribution and degrees of susceptibility for landslide-prone regions (Colkesen et al. 2016). To achieve this goal and to mitigate the destructive impacts of this phenomenon, landslide susceptibility maps can serve as an appropriate tool for increasing awareness and predicting future hazards (Feizizadeh et al. 2017). Based on previous landslides and identical physical features in similar areas, a landslide susceptibility map provides important signs regarding the locations where future landslides are likely to occur (Pradhan et al. 2017).

The Alborz Mountain has always been subject to the natural disasters such as landslide due to its being on the seismic belt of the Himalayas (Farrokhnia et al. 2011). In a study of identifying high-risk regions of the world with respect to landslide hazard, Nadim et al. (2006) reported that the Alborz and Zagros Mountains of Iran were among the areas with moderate to high landslide risks. In addition, according to the National Committee on Natural Disaster Reduction of the Iranian Ministry of Interior, the annual damage caused by landslides in Iran amounts to about 500 billion Rials (Arab Amiri et al. 2019). Consequently, if the loss of human life is taken into account, it is evident that zoning of the study area is necessary.

In the recent years, researchers have used different methods and their combinations to zone the areas susceptible to landslide in different areas worldwide that can generally classify into two quantitative and qualitative groups. The qualitative approaches, also known as knowledgedriven approaches, are the techniques of assigning weights to and rank criteria and sub-criteria based on experts' knowledge and experience and also on mathematical relations defined for each method. Some of these methods, which have been used in various studies and have yielded acceptable results, include the AHP (Zhang et al. 2016; Pourghasemi and Rossi 2017; Yan et al. 2019; Du et al. 2019) and hybrid methods such as MCDA and MCE (Kavzoglu et al. 2014; Erener et al. 2016; Kumar et al. 2017) and the WLC (Kouli et al. 2014; Ahmed 2015). The second group, also known as data-driven approaches, consists of the techniques which are not influenced by experts' opinions in the computational process. Instead, the relationship between the landslides and the effective parameters is determined by using probabilistic equations.

82 These methods, which have been used repeatedly in various studies on landslides, include 83 bivariate and multivariate probability models such as frequency ratio (FR) (Hong et al. 2017; 84 Sharma and Mahajan 2018; Berhane et al., 2020), weight of evidence (WoE) (Kayastha et al. 85 2013; Ding et al. 2017; Cui et al. 2017) and logistic regression (LR) (Wang et al. 2015; Oh et 
al. 2018; Pham et al. 2019) as well as soft computing methods such as artificial neural network (ANN) (Polykretis et al. 2014; Bui et al. 2016; Pham et al. 2017; Zhu et al. 2018; Moayedi et al. 2018), fuzzy logic (Pradhan et al. 2011; Ramesh and Anbazhagan 2015; Turan et al. 2020), adaptive neuro-fuzzy inference system (ANFIS) (Aghdam et al. 2017; Polykretis et al. 2019; Paryani et al. 2020), random forest (RF) (Kim et al. 2018) and support vector machine (SVM) (Pradhan 2013; Oh et al. 2018). According to the literature review, it is clear that although these models have effective performance in computational process, hybrid methods performs a strong structure to achieve more accurate results. Youssef et al. (2015) combined logistic regression and frequency ratio methods to landslide susceptibility mapping in Saudi Arabia. They concluded that ensemble of FR-LR model combining models has better results than using them alone. In another study, Aghdam et al. (2017) combined FR and WoE statistical methods with ANFIS algorithms to produce landslide susceptibility map of the Zagros Mountains in Iran. Their results indicated that FR-ANFIS and WoE-ANFIS have better performance compared with FR and WoE. It seems that using new methods is necessary to achieve more accurate results. Therefore, achieving optimal results relies on (a) the quality of the input data, (b) the structure of the model, used (Adineh et al. 2018).

In comparison with other studies, the research innovation of this study was to train the ANFIS method through the new multi-criteria decision-making method BWM (ANFIS-BWM) as a new hybrid model and compare it with the hybrid ANFIS-SWARA model. In other words, the weights obtained from BWM and SWARA methods were used as ANFIS input data. Landslide susceptibility maps were then generated for both models, and their performance accuracy was estimated by using the ROC curves. Finally, the results were compared to determine which of the two BWM and SWARA approaches were able to train the ANFIS network better and generate more realistic maps.

\section{Study Region}

112 With an area of $8604 \mathrm{~km}^{2}$, the Khalkhal-Tarom Basin is located on the southern slopes of the 113 Alborz mountain range along from $47^{\circ} 42^{\prime} 44^{\prime \prime}$ to $49^{\circ} 10^{\prime} 34^{\prime \prime}$ and $36^{\circ} 37^{\prime} 22^{\prime \prime}$ to $37^{\circ} 56^{\prime} 35^{\prime \prime}$

114 (Fig. 1). Approximately $92 \%\left(7967 \mathrm{~km}^{2}\right)$ of the Basin consists of highlands and the remainder 115 of plains. The highest and lowest elevations are $3314 \mathrm{~m}$ and $288 \mathrm{~m}$, respectively. The data from 116 the climatological stations of Iran Meteorological Organization and Ministry of Energy were 117 utilized to estimate temperature and precipitation. The average annual temperature in the region 118 is about $10.5^{\circ} \mathrm{C}$; while, the coldest month is February, and the warmest is August. In addition, 119 the average annual rainfall is about $375 \mathrm{~mm}$. The difference in precipitation levels in the 
120 highlands on the two sides of the main river (the Ghezel Ozan River) results from the

121 differences in the prevailing climatic conditions in the areas adjacent to the study area.

122 Although the study area has diverse lithology, pyroclastic rocks of Karaj Formation cover most

123 of its surface area. Regarding land use, range lands are the largest land cover class; however,

124 agricultural lands and orchards cover nearly $16 \%$ of the land area in the basin and exhibit an

125 increasing trend given the population increase. Given the existence of economic infrastructures

126 and the growing residential areas in future, zoning of landslide-prone regions seems to be

127 vitally important.

128

129 Database Development and Data Preparation

130 It is necessary to create database in any study of geographical information system. The 131 landslide zoning is no exception, and database creation including inventory map and

132 conditioning factors is considered as the first and the most important step in this process. The 133 landslide inventory map shows the locations and spatial distribution of landslides that happened 134 in the past. Since it is crucial to pinpoint the locations of the past and present landslides in order 135 to predict future high-risk areas, preparation of a landslide inventory map is a requisite to any 136 study on landslides (Regmi et al. 2013). Information on the locations of past landslides and 137 their spatial distributions was obtained from the Forest, Rangeland and Watershed 138 Organization of Iran (Fig. 1). According to Figure 1, the inventory map was employed to 139 randomly select 172 ( or $70 \%$ ) of the 242 landslides that have occurred in the region for training 140 the data and the $30 \%$ for model validation.

141 Various factors including geology, hydrology, geomorphology, climate and topography 142 affect slope instability. Determination of these factors is among the basic, and initial steps in 143 landslide zoning. In this study, thirteen conditioning factors including slope angle, slope aspect, 144 altitude, topographic wetness index (TWI), plan curvature, profile curvature, distance to roads, 145 distance to streams, distance to faults, lithology, land use, rainfall, normalized difference 146 vegetation index (NDVI) were selected based on the characteristics of the study area, experts 147 opinion and previous studies for the spatial modeling of the landslides (Table 1). According 148 to Table 1, these thirteen factors were determined by using the information obtained from the 149 related organizations and the reference data. Following that, ArcGIS was employed to generate 150 and digitalize the maps (30-×30-m pixels). Raster data models of the layers were then prepared 151 by using the selected methods.

152 In order to prepare the different information layers, the digital elevation model (DEM) was 153 prepared first using ASTER satellite images. DEM is one of the most important databases in 
154 any landslide study because preparation of some important thematic maps depends on it. The 155 slope angle, slope aspect, altitude, TWI and plan and profile curvature layers were extracted 156 from the DEM (Fig. 2 a-f). The other considered factors (distance to roads, distance to streams, 157 distance to faults, lithology, land use, rainfall and the Normalized Difference Vegetation Index 158 were then determined, respectively (Fig. 2 g-m). In addition, the conditioning factors were 159 categorized based on experts' opinions, previous studies and study area characteristics.

160 The slope degree is always considered as an essential factor in analyzing the areas susceptible to landslide (Umar et al. 2014), because it is the major cause of mass movements. Exposure to sunlight, dry winds, and increased relative humidity due to rainfall are all factors associated with slope aspect that trigger landslides (Kavzoglu et al. 2013). Therefore, slope aspect has

164 always been consideration by researchers. This factor is divided into 9 classes. Altitude is not 165 directly involved in the occurrence of landslides; however, other factors related to it such as 166 tectonic activity, weathering and climate change influence the entire process (Rozos et al. 167 2008). The topographic wetness index is a useful tool for estimating moisture conditions at 168 basin scale (Grabs et al. 2009). This factor was used due to the varying humidity conditions in 169 the study area. The values obtained from the slope curvature show the morphology of the 170 different elevation points (Erener et al. 2010). In this paper, both the profile curvature curve 171 and the plan curvature were taken into account. The former indicates the velocity and process 172 of sediment transport and the second the divergence and convergence of the flow passing 173 through the surface (Dehnavi et al. 2015). Road construction, especially when engineering 174 principles are ignored, reduces slope stability and consequently triggers landslides (Moosavi 175 and Niazi 2015). Therefore, the distance from the road has always attracted the interest of researchers (Xiao et al. 2019; Bui et al. 2012). Streams decrease shear strength by eroding the materials from the toe of the slope. Consequently, the factor of distance from the stream is very 178 important in relation to slope stability (Achour et al. 2017). Faults, especially in seismic zones, 179 play a significant role in triggering mass movements. They either act directly as a triggering 180 factor for landslides or indirectly by causing fractures in slope layers that lead to the penetration 181 of water into joints and fissures, thereby reducing the shear strength of materials constituting 182 the slope that results in the occurrence of landslides. lithology as a geological factor has always 183 been important role in predicting landslide occurrence probability because different lithologic 184 units with varying degrees of permeability influence slope stability (Chalkias et al. 2014). Due 185 to their impacts on slope instability, different types of land use have always attracted many 186 researchers in their research on landslides (Conforti et al. 2013; Dou et al. 2014). The 187 precipitation factor was used in this research because the amount of precipitation varies with 
188 changes in elevation and precipitation directly and indirectly influences landslide occurrence.

189 The NDVI index was calculated to analyze the effect of vegetation on slope instability:

$190 N D V I=\frac{N I R-R}{N I R+R}$

192 The NDVI benefits from the ratio of near-infrared (NIR) reflection to red (R) reflection to

193 estimate vegetation density (Hall et al. 1995).

194

195 Methodology

196 Step-wise weight assessment ratio analysis (SWARA) model

197 This is a multi-criteria decision-making method with an ultimate objective like that of other

198 similar approaches: assigning weights to criteria and sub-criteria. Since its introduction by 199 Keršulien et al. in 2011, researchers have used it to analyze various areas (Mardani et al. 2015). 200 An advantage of this method is its flexibility that allows experts to prioritize the criteria based 201 on the existing conditions. The main feature of this approach is its capability in estimating 202 experts' opinions in relation to the relative importance of the criteria in order to determine their 203 weights (Keršulien et al. 2011). This procedure consists of the following steps:

1. Selecting the required criteria and ranking them according to their degrees of importance (the most important criteria take the highest position of ranking and the least important ones the lowest).

2. Calculating the coefficient $\mathrm{K}_{\mathrm{j}}$, which is a function of the relative importance of each criterion.

3. Determining the initial weight of each criterion.

212 The final weight for each criterion is calculated through the following equations (Keršulien et 213 al. 2011):

$215 \quad S_{j}=\frac{\sum_{i}^{n} A_{i}}{n}$

216 In this equation, $\mathrm{j}$ and $\mathrm{n}$ represent the criterion number and the number of experts, respectively.

217 The value of $A_{i}$ also indicates the suggested rating of each criterion.

$218 \quad \mathrm{~K}_{\mathrm{j}}=\mathrm{S}_{\mathrm{j}}+1$

$219 Q_{j}=\frac{X_{j}-1}{K_{j}}$ 
220 Here, $\mathrm{K}_{\mathrm{j}}$ and $\mathrm{Q}_{\mathrm{i}}$ are functions of the relative importance and initial weight of each criterion, 221 respectively.

$222 \quad W_{j}=\frac{Q_{j}}{\sum_{j=1}^{m} Q_{j}}$

223 In this formula, $\mathrm{j}$ represents the criterion number, and $\mathrm{m}$ shows the number of criteria when $\mathrm{W}_{\mathrm{j}}$

224 indicates the final weight.

226 The final weight $\left(\mathrm{W}_{\mathrm{j}}\right)$ obtained for each sub-criteria in this study indicates the relationship 227 between landslides and conditioning factors. The larger/smaller the final weight of a sub228 criterion is, the higher/lower its importance in landslide occurrence will be.

\section{Best-worst multi-criteria decision making (BWM) model}

231 The best-worst method (BWM) is one of the newest and most efficient multi-criteria decision232 making approaches introduced in 2015 by Rezaei to calculate the final weights of criteria and 233 sub-criteria in decision-making problems. As in other MCDM methods such as AHP, pair-wise 234 comparisons are used in BWM. However, the differences in the final weight calculation in this 235 method have made the final result much more realistic and consistent than methods such as 236 AHP. The advantages of BWM over AHP are that fewer pair-wise comparisons are used, the numbers used for pair-wise comparisons are integers ranging between 1 and 9 , and there is no need for fractional numbers. It is also possible to integrate the BWM with other MCDM methods (Ahmad et al. 2017). The various steps in this method and its algorithms for problem solving are as follows (Rezaei 2015):

1. Specifying the decision-making criteria for evaluation. The set of criteria is defined as $\left\{\mathrm{C}_{1}, \mathrm{C}_{2}, \ldots, \mathrm{C}_{\mathrm{n}}\right\}$.

2. Determining the best (B) and worst (W) criteria by the experts. The best criterion

250 Here, $\alpha_{\mathrm{B} 1}$ represents the preference of the best criterion $(B)$ over the criterion $\mathrm{j}\left(\alpha_{\mathrm{BB}}=1\right)$ (Fig. 4). 
4. Determining the priority of all the criteria over the worst one $(\mathrm{W})$. The preference vector for this phase is as follows:

$254 \mathrm{~A}_{\mathrm{W}}=\left(\alpha_{1 \mathrm{~W}}, \alpha_{2 \mathrm{~W}}, \ldots, \alpha_{\mathrm{nW}}\right)^{\mathrm{T}}$

256 Here, $\alpha_{\mathrm{jw}}$ is the preference of the $\mathrm{j}$ criterion over the worst one (W) ( $\left.\alpha w w=1\right)$ (Fig. 4).

5. Calculating the final weights of the criteria. The following equations are used for this purpose:

259 Min $\varepsilon_{\text {, }}$

260 s.t.

$261\left|\frac{W_{B}}{W_{j}}-\alpha_{B j}\right| \leq \varepsilon, \forall j=1,2, \ldots, n$

262

$$
\left|\frac{W_{j}}{W_{W}}-\alpha_{j W}\right| \leq \varepsilon, \forall j=1,2, \ldots, n
$$

$264 \sum_{j}^{W} w_{j}=1$

$$
\mathrm{W}_{\mathrm{j}} \geq 0, \forall \mathrm{j}=1,2, \ldots, \mathrm{n}
$$

267 The values of the final optimum weights $\left(\mathrm{W}_{1}^{*}, \mathrm{~W}_{2}^{*}, \ldots . \mathrm{W}_{\mathrm{n}}^{*}\right)$ and $\varepsilon^{*}$ are obtained by Equations 8.

268 In addition, the consistency ratio for each criterion can be estimated by using the consistency

269 index table (Table 3 ) and the $\varepsilon^{*}$ value. The following equation states that:

270 Consistency Ratio $=\frac{\varepsilon_{\mathrm{r}}^{*}}{\text { Consistency Index }}$

271 It is evident that the closer the value of the consistency index is to zero, the more realistic the

272 results will be. Refer to Rezaei et al. (2015) for more details of this method.

\section{Adaptive neuro fuzzy inference system (ANFIS)}

275 Although a fuzzy inference system (FIS) using "if-then" rules can analyze complex processes, 276 it is unable to perform the learning process. The adaptive neuro fuzzy inference system 277 (ANFIS) (Jang 1993) is one of the most widely used fuzzy systems for modeling nonlinear 278 problems. This approach, developed by combining a FIS and an artificial neural network 279 (ANN), utilizes the advantages of both approaches to solve problems. The ANN model is able 280 to optimize the fuzzy logic solution through the learning process (Oh and Pradhan 2011). The 281 details of the ANFIS model structure are as follows: 
283 The ANFIS structure was developed by using the Takagi-Sugeno fuzzy rule base (the details 284 are presented in equations 10 and 11).

286 Rule 1: if $\mathrm{x}$ is $A_{1}$ and $\mathrm{y}$ is $B_{1}$ then $f_{1=} p_{1} x+q_{1} y+r_{1}$

287 Rule 2: if $\mathrm{x}$ is $A_{2}$ and $\mathrm{y}$ is $B_{2}$ then $f_{2=} p_{2} x+q_{2} y+r_{2}$

Here, $\mathrm{x}$ and $\mathrm{y}$ are the system inputs and A1, A2, B1 and B2 are fuzzy membership functions.

290 In addition, $p_{i}, q_{i}$ and $r_{i}(\forall i=1,2)$ are the parameters of the output function (Jang 1993). In

291 general, the ANFIS structure is made of five layers described below (Fig. 5):

293 Layer 1: This layer is responsible for the fuzzification of the variables, and the nodes in this 294 layer are adaptive nodes.

$295 O_{A_{i}}^{1}=\mu_{A_{i}}(x), \quad \mathrm{i}=1,2$

$296 O_{B_{i}}^{1}=\mu_{B_{i}}(y), \quad \mathrm{i}=1,2$

297 Here, $\mathrm{i}$ represents the related node and $\mathrm{x}$ and $\mathrm{y}$ its input variables, $\mathrm{A}_{\mathrm{i}}$ and $\mathrm{B}_{\mathrm{i}}$ are linguistic terms and $\mu_{\mathrm{Ai}}(\mathrm{x})$ and $\mu \mathrm{B}_{\mathrm{i}}(\mathrm{y})$ the membership functions of the node $\mathrm{i}$.

Layer 2: In this section, every node is a fixed node and each one is responsible for multiplying signals entering it. The nodes are named by the $\Pi$ label and their outputs are as follows (Oh and Pradhan 2011):

303

$O_{2, i}=\mu_{A_{i}}(x) \cdot \mu_{B_{i}}(y)=W_{i}, \quad$ for $i=1,2$

Here, $\mathrm{W}_{\mathrm{i}}$ (the so called firing strength of each fuzzy rule) represents each node's output.

Layer 3: This layer has the task of normalizing the output of the second layer. Therefore, the nodes, which are fixed ones and named by the $\mathrm{N}$ label, normalize the input values (Equation 15). The numerator of the fraction includes the firing strength of each fuzzy rule, and the denominator includes the total firing strength of each rule.

$O_{3, i}=\frac{W_{i}}{W_{1}+W_{2}}=\bar{W}_{i}$ for $i=1,2$

313 Layer 4: This is considered the second adaptive layer in the ANFIS structure and each node's output is obtained from the following equation: 
317 In this equation, $\bar{W}_{i}$ is the normalized firing strength of the third layer. $p_{i}, q_{i}$ and $r_{i}$ are the 318 variable parameters (also referred to as the result parameters) of the node $i$.

320 Layer 5: The only node existing in this layer is fixed node labeled $\Sigma$. This node sums up all the input signals and calculates the resulting output (Equation 17).

$322 O_{5, i}=\sum_{i} \bar{W}_{i} f_{i}=\frac{\sum_{i} W_{i} f_{i}}{\sum_{i} W_{i}}$

324 For more details on the layers and the algorithms, refer to Jang (1993) and Jang and Sun

325 (1995). Figure 3 shows the process of the study including methods and type of combination 326 used.

\section{Results and Validation}

329 Table 2 shows the weights obtained from the SWARA model and BWM. The values for the 330 slope factor indicate that most of the landslides that occurred in the study area were of the 5$15^{\circ}$ class with weights of 0.405 and 0.409 , respectively. Among the different slope aspects, the north-east aspect, with the values of 0.486 (SWARA) and 0.249 (BWM), had the highest effect on landslide occurrence. In relation to the altitude factor, the 1500-1700 $\mathrm{m}$ class had the highest impact on landslide (with values of 0.454 and 0.212 for SWARA and BWM, respectively). The outputs of the SWARA model for the TWI showed that the 5.65-7.31 and 7.31-9.87 classes with values of 0.482 and 0.249 , respectively, had the highest probabilities of landslide occurrence. For the BWM, the 5.65-7.31 and 7.31-9.87 classes with the weight of 0.371 had the greatest impact on landslide occurrence. For the plan curvature factor, according to Table 2, the maximum weights obtained from the SWARA and BWM were for the convex class with weights of 0.410 and 0.769 , respectively. For the profile curvature factor, the highest SWARA weight (0.489) was that of the concave class and for BWM the highest value (0.470) was that

342 of the concave and convex classes. Results obtained from SWARA indicated that the distance 343 to road, distance to stream and distance to fault in the 0-100 m, 0-100 m and $1200-1500 \mathrm{~m}$ 344 classes with weights of $0.311,0.404$ and 0.386 , respectively, had the highest influence on landslide occurrence. As in the SWARA method, in the BWM also the same classes had the 346 highest weights with the values of 0.397, 0.297 and 0.330, respectively. Concerning lithology, 347 the highest value in the SWARA method (0.344) was that of the Jl class and the highest in the 
348 BWM (0.2) those of the JI and PIQc classes. For the land use factor, the agriculture class in 349 both models had the strongest relationship with landslide occurrence with values of 0.27 and 350 0.505, respectively. Landslides were more likely to occur with increases in rainfall. For the 351 precipitation factor, 332.9 - $387.65 \mathrm{~mm}$ of rainfall had the highest weights in the SWARA 352 model and BWM (0.352 and 0.647, respectively). In relation to the NDVI factor, the likelihood 353 of landslide occurrence was greatest for the class $>0.5$ with the weights of 0.356 and 0.574 for 354 the SWARA method and BWM, respectively.

\section{Integration of the ANFIS with SWARA and BWM}

In this study, MATLAB was employed to construct the ANFIS model and the SWARA method and BWM to feed it for training the network. For this purpose, all the data were first divided into the training and testing sets. As mentioned earlier $70 \%$ of the data (172 landslide locations) were allocated for training and 30\% (70 landslide locations) for testing, and they were assigned the value of 1. Using the training data and the SWARA model and BWM, the weights of the sub-criteria were calculated (Table 2). In the next step, 242 non-landslide points, showing the total number of data, were created in the non-landslide areas. Then 0 was allocated to each of them. Out of these non-landslide points, 70\% (172) points were selected randomly and considered for training the network. Next, 172 landslide and non-landslide points (with values of 1 and 0 ) were overlaid upon the conditioning factors and the value of each one was determined. This process was carried out once for the SWARA model and once for the BWM. The values obtained from the overlaying were used as input data for ANFIS training. After ANFIS training using the BWM method and SWARA, all the pixels were entered into MATLAB and the final value of each pixel was determined using the created network. Finally, landslide susceptibility maps were prepared for the hybrid ANFIS-BWM and ANFIS-SWARA models (Fig. 7). The prepared maps were divided into five classes with sensitivity degree of very low, low, moderate, high, and very high. Figure 8 shows the percent area for each class in the ANFIS-SWARA and ANFIS-BWM hybrid models. It is quite clear that the class with very high landslide susceptibility had the lowest area in both LSMs with values of $16.21 \%$ and $18.65 \%$, respectively (Table 4). In addition, the classes with high and low landslide susceptibility had the largest areas with the values of. $23.01 \%$ and $20.50 \%$ for ANFIS-SWARA and ANFIS-BWM, respectively.

\section{Models validation and comparison}


381 Validation is a very important step in estimating the accuracy of a method in producing 382 landslide susceptibility maps. In this study, validation was performed by using $30 \%$ of landslide 383 and non-landslide locations (72 points with values of 0 and 1) in two stages. In the first stage, 384 the mean square error was calculated to estimate the accuracy of ANFIS trained network using 385 SWARA and BWM methods. MSE and RMSE are defined as follows:

386

$387 \quad M S E=\frac{1}{n} \sum_{j=1}^{n}\left(T_{j}-\bar{T}_{j}\right)^{2}$

$388 \quad R M S E=\sqrt{\frac{1}{n} \sum_{j=1}^{n}\left(T_{j}-\bar{T}_{j}\right)^{2}}$

where, $T_{j}$ is the target values and $\bar{T}_{j}$ is the output values and $\mathrm{n}$ is the total number of samples.

391 RMSE is the square root of MSE.

393 The lower MSE value is (closer to zero) the lower the amount of error in the final prediction 394 and hence the more accuracy the modeling will be. Fig. 6c shows MSE and RMSE for the test 395 dataset. The results showed that the MSE values for the ANFIS-SWARA and ANFIS-BWM 396 models are 0.299 and 0.242 , respectively. As the results indicate, the new BWM method outperformed the SWARA model in training the ANFIS.

398 In the second stage the LSMs were evaluated using the ROC curve. The ROC curve is a 399 graphical representation of the balance between negative and positive error values that can quantitatively estimate the model accuracy. The area under the curve (AUC) illustrates the predicted value of the system by describing its ability in correctly estimating the occurrence of the event (landslide) and the non-occurrence of the event (non-landslide) (Yan et al. 2018).

403 Therefore, the larger the area under (AUC) the curve is the more accurate the model will be 404 and the lower AUC show weak performance of the model. Further details on this curve for 405 validating landslide susceptibility maps are provided in articles by Pourghasemi et al. 2013 and 406 Fan et al. 2017.

407 In this study, 72 landslide and non-landslide points were overlaid upon the conditioning 408 factors to plot the ROC curves. The values obtained for each point were then used as input data. 409 Figure 9 shows the ROC curves for the methods. In this figure, the areas under the curves for 410 the ANFIS-SWARA and ANFIS-BWM hybrid models are 0.736 and 0.75 , respectively. The 411 results obtained from the evaluation of the zoning suggested that both models were able to 
412 predict the landslide prone areas well; however, the ANFIS-BWM model was more accurate 413 and, hence, yielded more reliable outputs.

\section{Discussion}

417 Landslide spatial modeling is a nonlinear and complex problem because it is affected by 418 various parameters. Although there are different methods for landslide susceptibility zoning, 419 the important point is which method or combination of methods should be used, depending on 420 the features of the study area, in order to obtain the best results. The novelty of this study is to 421 produce a new hybrid ANFIS-BWM model and compare it with ANFIS-SWARA to determine 422 the best combination. For this purpose, a database was first developed to contain the inventory 423 map and factors influencing landslides. In the next step, the SWARA and BWM approaches 424 were then executed by using the database and experts' opinions, and the weights of the sub425 criteria were determined. The weights obtained from each of the two approaches were entered separately in MATLAB to train ANFIS. After developing the network and calculating the final value of each pixel, the LSMs were generated, and the accuracy of each map was assessed by using the ROC curve. The resultant validation output indicated that the new BWM produced more realistic results than the SWARA method which trained the ANFIS model well and obtained an acceptable output from it. Since bringing the prediction closer to reality is the most important objective in complex environmental issues such as landslides, it is necessary to compare newly introduced methods with the previous ones in order to achieve more optimal results.

434 The research models have attracted the interest of landslide researchers. Oh and Pradhan. 435 (2011) employed the ANFIS model with the triangular, trapezoidal, Gaussian, 2-sided 436 Gaussian, generalized bell, sigmoid 1, sigmoid 2 and polynomial membership functions for 437 landslide spatial modeling on Penang Island in Malaysia. For this purpose, they first determined 438 the relationships between the eight effective factors and the previous landslides by using the 439 frequency ratio method. The ANFIS model was then implemented in MATLAB and to estimate 440 the values obtained from the frequency ratio method and its accuracy through the ROC curve. 441 They showed that the triangular, trapezoidal, generalized bell and polynomial membership 442 functions were slightly more accurate than the others, although all the membership functions 443 that were used yielded very good results with accuracies higher than $84 \%$. In order landslide 444 spatial modelling for Iran, Dehnavi et al. (2015) integrated the SWARA multi-criteria decision445 making approach with the ANFIS method. In the first step, the SWARA model was used to 
specify the weights of sub-criteria, and the LSM was then generated. In the second step, the

447 SWARA model weights were utilized to train the ANFIS and generate the map for the hybrid 448 ANFIS-SWARA landslide susceptibility model. They found that the ANFIS-SWARA hybrid model with the area under the curve of 0.8 yielded a more accurate prediction than the SWARA method with the area under the curve of 0.78. Gigovic et al. (2019) integrated the BWM with the WLC and OWA methods for zoning regional landslides in western Serbia. For this purpose, they first created a database that included 15 conditioning factors and 1082 previous landslides. The normalized weights of the effective factors were then calculated by using the BWM. The WLC and OWA methods were then employed to produce LSMs. Finally, the performance of each map was assessed by through the ROC curve. They showed that the OWA method with 94.1\% accuracy outperformed the WLC method that had the accuracy of $90.5 \%$.

In this study, the important of using new models to improve the performance of machine learning methods was shown. Based on the results shown in table 2, although both methods are of the type of MCDM and include values between 0 and 0.5, the new BWM model performs better compared to SWARA model. Therefore, the type of model that is used to determine the correlation between conditioning factors and the landslide occurrence is effective in improving the results. According to the research findings, the employed methods performed well in estimating landslide prone areas. In addition, the use of the two ANFIS-BWM and ANFISSWARA hybrid models with the accuracies of $75 \%$ and $73.6 \%$, respectively, confirmed this statement. It is recommended to integrate SWARA and BWM multi-criteria decision-making models with machine learning methods such as ANFIS for other similar areas.

\section{Conclusion}

469 Known as natural destructive ground-deforming phenomena, landslides have occurred in all 470 historical periods. Evaluation of landslide susceptibility maps is a multistage and complicated 471 process and, therefore, the careful selection and execution of the stages of the model will result 472 in generation of maps yielding better results.

473 In the present study, a new comparison was drawn between two multi-criteria decision474 making methods to train the ANFIS model. For this purpose, it was decided to determine the 475 relationships between landslides and effective factors by using the new BWM and the SWARA 476 model. The weights obtained from both methods were then employed to train the ANFIS. 477 Finally, the landslide susceptibility maps were generated using the ANFIS-SWARA and 478 ANFIS-BWM ensemble models. The results of validation using the ROC curve showed that 479 the ANFIS-BWM model with a 75\% prediction accuracy outperformed the ANFIS-SWARA 
480 model with a 73.6\% prediction accuracy. Although both the BWM and the SWARA technique 481 were multi-criteria decision-making models, their outputs differed in types of ranking and 482 weighting. Therefore, it is essential to decide the output of which method should be utilized to 483 train a machine learning model. Since these models yielded good results, they are 484 recommended for use in other similar areas because they can substantially help land use 485 managers and planners in making important decisions.

486

487 Declarations

488 Ethics approval and consent to participate.

489 Not applicable.

490 Consent for publication

491 Not applicable.

492 Availability of data and materials

493 All data generated or analyzed during this study are confidential.

494 Competing interests

495 The authors declare that they have no competing interests.

496 Funding

497 Not applicable.

498 Code availability (software application or custom code)

499 Not applicable.

500 Authors' contributions

501 All authors contributed to the study conception and design. Data collection and material

502 preparation were performed by SP. Development and design of methodology and creation of 503 models were performed by SP and AN. BP consulted for the methodology application. AN 504 was the supervisors of the work. The first draft of the manuscript was written by SP and AN 505 and BP commented on previous versions of the manuscript. 


\section{References}

507 Achour Y, Boumezbeur A, Hadji R, Chouabbi A, Cavaleiro V, Bendaoud EA (2017) Landslide

508 susceptibility mapping using analytic hierarchy process and information value methods along a highway road section in Constantine, Algeria. Arab J Geosci. 10:194.

Adineh F, Motamedvaziri B, Ahmadi H, Moeini A (2018) Landslide susceptibility mapping using Genetic Algorithm for the Rule Set Production (GARP) model. J Mt Sci. 15:2013-2026.

514 Aghdam IN, Pradhan B, Panahi M (2017) Landslide susceptibility assessment using a novel 515 hybrid model of statistical bivariate methods (FR and WOE) and adaptive neuro-fuzzy 516 inference system (ANFIS) at southern Zagros Mountains in Iran. Environ Earth Sci. 76:237.

518 Ahmad WNKW, Rezaei J, Sadaghiani S, Tavasszy LA (2017) Evaluation of the external forces 519 affecting the sustainability of oil and gas supply chain using Best Worst Method. J Clean 520 Prod. 153:242-252.

522 Ahmed B (2015) Landslide susceptibility mapping using multi-criteria evaluation techniques 523 in Chittagong Metropolitan Area, Bangladesh. Landslides 12:1077-1095. susceptibility mapping using numerical risk factor bivariate model and its ensemble with linear multivariate regression and boosted regression tree algorithms. J Mt Sci. 16:595-618.

529 Baena JAP, Scifoni S, Marsella M, De Astis G, Fernández CI (2019) Landslide susceptibility 530 mapping on the islands of Vulcano and Lipari (Aeolian Archipelago, Italy), using a multi531 classification approach on conditioning factors and a modified GIS matrix method for areas lacking in a landslide inventory. Landslides 16:969-982.

534 Berhane G, Kebede M, Alfarrah N (2020) Landslide susceptibility mapping and rock slope 535 stability assessment using frequency ratio and kinematic analysis in the mountains of Mgulat 536 area, Northern Ethiopia. Bull Eng Geol Environ. 1-17. https://doi.org/10.1007/s10064-020537 01905-9 
539 Bui DT, Pradhan B, Lofman O, Revhaug I, Dick OB (2012) Spatial prediction of landslide 540 hazards in Hoa Binh province (Vietnam): a comparative assessment of the efficacy of 541 evidential belief functions and fuzzy logic models. Catena 96:28-40.

543 Bui DT, Tuan TA, Klempe H, Pradhan B, Revhaug I (2016) Spatial prediction models for 544 shallow landslide hazards: a comparative assessment of the efficacy of support vector 545 machines, artificial neural networks, kernel logistic regression, and logistic model 546 tree. Landslides 13:361-378.

548 Chalkias C, Ferentinou M, Polykretis C (2014) GIS-based landslide susceptibility mapping on 549 the Peloponnese Peninsula, Greece. Geosciences 4:176-190.

550

551 Colkesen I, Sahin EK, Kavzoglu T (2016) Susceptibility mapping of shallow landslides using 552 kernel-based Gaussian process, support vector machines and logistic 553 regression. J Afr Earth Sci. 118:53-64.

555 Conforti M, Pascale S, Robustelli G, Sdao F (2014) Evaluation of prediction capability of the 556 artificial neural networks for mapping landslide susceptibility in the Turbolo River catchment 557 (northern Calabria, Italy). Catena 113:236-250.

559 Cui K, Lu D, Li W (2017) Comparison of landslide susceptibility mapping based on statistical 560 index, certainty factors, weights of evidence and evidential belief function models. Geocarto 561 Int. 329:935-955.

563 Dehnavi A, Aghdam IN, Pradhan B, Varzandeh MHM (2015) A new hybrid model using step564 wise weight assessment ratio analysis (SWARA) technique and adaptive neuro-fuzzy inference system (ANFIS) for regional landslide hazard assessment in Iran. Catena 135:122-148.

567 Ding Q, Chen W, Hong H (2017) Application of frequency ratio, weights of evidence and 568 evidential belief function models in landslide susceptibility mapping. Geocarto Int. 32:619569639. 
571 Dou J, Oguchi T, Hayakawa YS, Uchiyama S, Saito H, Paudel U (2014) GIS-based landslide 572 susceptibility mapping using a certainty factor model and its validation in the Chuetsu Area, 573 Central Japan. In Landslide science for a safer geoenvironment. p. 419-424.

574

575 Du G, Zhang Y, Yang Z, Guo C, Yao X, Sun D (2019) Landslide susceptibility mapping in the 576 region of eastern Himalayan syntaxis, Tibetan Plateau, China: a comparison between analytical 577 hierarchy process information value and logistic regression-information value methods. Bull 578 Eng Geol Environ. 78(6):4201-4215.

579

580 Erener A, Düzgün HSB (2010) Improvement of statistical landslide susceptibility mapping by 581 using spatial and global regression methods in the case of More and Romsdal 582 (Norway). Landslides 7:55-68.

583

584

585 Erener A, Mutlu A, Düzgün HS (2016) A comparative study for landslide susceptibility mapping using GIS-based multi-criteria decision analysis (MCDA), logistic regression (LR) and association rule mining (ARM). Eng Geol. 203:45-55.

Fan W, Wei XS, Cao YB, Zheng, B (2017) Landslide susceptibility assessment using the 590 certainty factor and analytic hierarchy process. J Mt Sci. 14:906-925.

592 Farrokhnia A, Pirasteh S, Pradhan B, Pourkermani M, Arian M (2011) A recent scenario of 593 mass wasting and its impact on the transportation in Alborz Mountains, Iran using geo594 information technology. Arab J Geosci. 4:1337-1349.

596 Feizizadeh B, Roodposhti MS, Blaschke T, Aryal J (2017) Comparing GIS-based support 597 vector machine kernel functions for landslide susceptibility mapping. Arab J Geosci. 10:122.

599 Gigović L, Drobnjak S, Pamučar D (2019) The application of the hybrid GIS spatial multi600 criteria decision analysis best - worst methodology for landslide susceptibility 601 mapping. ISPRS Int J Geo-Inf. 8:79.

602

603 Gutiérrez F, Linares R, Roqué C, Zarroca M, Carbonel D, Rosell J, Gutiérrez M (2015) Large 604 landslides associated with a diapiric fold in Canelles Reservoir (Spanish Pyrenees): Detailed 
605 geological - geomorphological mapping, trenching and electrical resistivity

606 imaging. Geomorphology 241:224-242.

607

608 Grabs T, Seibert J, Bishop K, Laudon H (2009) Modeling spatial patterns of saturated areas: A 609 comparison of the topographic wetness index and a dynamic distributed model. J 610 Hydrol. 373:15-23.

611

612 Hall FG, Townshend JR, Engman ET (1995) Status of remote sensing algorithms for estimation 613 of land surface state parameters. Remote Sens. Environ. 51:138-156.

614

615 Hong H, Chen W, Xu C, Youssef AM, Pradhan B, Tien Bui D (2017) Rainfall-induced 616 landslide susceptibility assessment at the Chongren area (China) using frequency ratio, 617 certainty factor, and index of entropy. Geocarto Int. 322:139-154.

618

619 Jang JS (1993) ANFIS: adaptive-network-based fuzzy inference system. IEEE Trans. Syst. 620 Man Cybern. 23:665-685.

621

622 Juliev M, Mergili M, Mondal I, Nurtaev B, Pulatov A, Hübl J (2019) Comparative analysis of 623 statistical methods for landslide susceptibility mapping in the Bostanlik District, 624 Uzbekistan. Sci Total Environ. 653:801-814.

625

626 Kavzoglu T, Sahin EK, Colkesen I (2014) Landslide susceptibility mapping using GIS-based 627 multi-criteria decision analysis, support vector machines, and logistic 628 regression. Landslides. 11:425-439.

629

630 Kayastha P, Dhital MR, De Smedt F (2012) Landslide susceptibility mapping using the weight 631 of evidence method in the Tinau watershed, Nepal. Nat Hazards. 63:479-498.

632

633 Keršulienè V, Turskis Z (2011) Integrated fuzzy multiple criteria decision-making model for 634 architect selection. Technol. Econ Dev Econ. 17:645-666.

635

636 Kim JC, Lee S, Jung HS, Lee S (2018) Landslide susceptibility mapping using random forest 637 and boosted tree models in Pyeong-Chang, Korea. Geocarto Int. 339:1000-1015. 
639 Kouli M, Loupasakis C, Soupios P, Rozos D, Vallianatos F (2014) Landslide susceptibility 640 mapping by comparing the WLC and WofE multi-criteria methods in the West Crete Island, 641 Greece. Environ Earth Sci. 72:5197-5219.

642

643 Kumar S, Srivastava PK, Snehmani (2017) GIS-based MCDA-AHP modeling for avalanche 644 susceptibility mapping of Nubra valley region, Indian Himalaya. Geocarto Int. 32:1254-1267. 645

646 Lin L, Lin Q (2017) Landslide susceptibility mapping on a global scale using the method of 647 logistic regression. Nat Hazards Earth Syst. Sci. 17:1411-1424.

648

649 Mardani A, Zavadskas EK, Khalifah Z, Zakuan N, Jusoh A, Nor KM, Khoshnoudi M (2017)

650 A review of multi-criteria decision-making applications to solve energy management 651 problems: Two decades from 1995 to 2015. Renew Sust Energ Rev. 71: 216-256.

652

653 Moayedi H, Mehrabi M, Mosallanezhad M, Rashid ASA, Pradhan B (2019) Modification of 654 landslide susceptibility mapping using optimized PSO-ANN technique. Eng Comput. 35:967655984.

656

657 Moosavi V, Niazi Y (2016) Development of hybrid wavelet packet-statistical models (WP658 SM) for landslide susceptibility mapping. Landslides 13:97-114.

659

660 Nadim F, Kjekstad O, Peduzzi P, Herold C, Jaedicke C (2006) Global landslide and avalanche 661 hotspots. Landslides 3:159-173.

662

663 Oh HJ, Pradhan B (2011) Application of a neuro-fuzzy model to landslide-susceptibility 664 mapping for shallow landslides in a tropical hilly area. Comput Geosci. 37:1264-1276.

665

666 Oh HJ, Kadavi PR, Lee CW, Lee S (2018) Evaluation of landslide susceptibility mapping by 667 evidential belief function, logistic regression and support vector machine models. GEOMAT 668 Nat Haz Risk. 9:1053-1070.

669

670 Paryani S, Neshat A, Javadi S, Pradhan B (2020) Comparative performance of new hybrid 671 ANFIS models in landslide susceptibility mapping. Nat Hazards. 1-28. 672 https://doi.org/10.1007/s11069-020-04067-9 
674 Pham, B. T., Bui, D. T., Pourghasemi, H. R., Indra, P., \& Dholakia, M. B. (2017). Landslide 675 susceptibility assesssment in the Uttarakhand area (India) using GIS: a comparison study of 676 prediction capability of naïve bayes, multilayer perceptron neural networks, and functional 677 trees methods. Theoretical and Applied Climatology, 128(1-2), 255-273.

678

679 Pham BT, Prakash I (2018) Machine learning methods of kernel logistic regression and 680 classification and regression trees for landslide susceptibility assessment at part of Himalayan area, India. Indian J Sci Technol. 11:1-11.

682

683 Pham BT, Prakash I (2019) Evaluation and comparison of LogitBoost Ensemble, Fisher's 684 Linear Discriminant Analysis, logistic regression and support vector machines methods for 685 landslide susceptibility mapping. Geocarto Int 34:316-333.

686

687 Polykretis C, Ferentinou M, Chalkias C (2015) A comparative study of landslide susceptibility 688 mapping using landslide susceptibility index and artificial neural networks in the Krios River and Krathis River catchments (northern Peloponnesus, Greece). Bull Eng Geol Environ. 74(1), $690 \quad 27-45$.

691

692 Polykretis C, Chalkias C, Ferentinou M (2019) Adaptive neuro-fuzzy inference system 693 (ANFIS) modeling for landslide susceptibility assessment in a Mediterranean hilly area. B Eng 694 Geol Environ. 78:1173-1187.

695

696 Pourghasemi HR, Moradi HR, Aghda SF (2013) Landslide susceptibility mapping by binary 697 logistic regression, analytical hierarchy process, and statistical index models and assessment 698 of their performances. Nat Hazards. 69:749-779.

699

700 Pourghasemi, H. R., \& Rossi, M. (2017). Landslide susceptibility modeling in a landslide prone 701 area in Mazandarn Province, north of Iran: a comparison between GLM, GAM, MARS, and 702 M-AHP methods. Theoretical and Applied Climatology, 130(1-2), 609-633.

703

704 Pradhan B (2011) Manifestation of an advanced fuzzy logic model coupled with Geo705 information techniques to landslide susceptibility mapping and their comparison with logistic 706 regression modelling. Environ Ecol Stat. 18:471-493. 
708 Pradhan B (2013) A comparative study on the predictive ability of the decision tree, support 709 vector machine and neuro-fuzzy models in landslide susceptibility mapping using 710 GIS. Comput Geosci. 51:350-365.

712 Pradhan B, Seeni MI, Kalantar B (2017) Performance evaluation and sensitivity analysis of 713 expert-based, statistical, machine learning, and hybrid models for producing landslide 714 susceptibility maps. In: Laser scanning applications in landslide assessment. Springer 715 international publishing, pp. 193-232. Springer, Cham.

716

717 Umar Z, Pradhan B, Ahmad A, Jebur MN, Tehrany MS (2014) Earthquake induced landslide 718 susceptibility mapping using an integrated ensemble frequency ratio and logistic regression 719 models in West Sumatera Province, Indonesia. Catena 118:124-135.

721 Ramesh V, Anbazhagan S (2015) Landslide susceptibility mapping along Kolli hills Ghat road section (India) using frequency ratio, relative effect and fuzzy logic models. Environ Earth Sci. 73:8009-8021.

724

725 Regmi AD, Devkota KC, Yoshida K, Pradhan B, Pourghasemi HR, Kumamoto T, Akgun A 726 (2014) Application of frequency ratio, statistical index, and weights-of-evidence models and 727 their comparison in landslide susceptibility mapping in Central Nepal Himalaya. Arab J 728 Geosci. 7:725-742.

730 Rezaei J (2015) Best-worst multi-criteria decision-making method. Omega 53:49-57.

732 Rozos D, Pyrgiotis L, Skias S, Tsagaratos P (2008) An implementation of rock engineering 733 system for ranking the instability potential of natural slopes in Greek territory. An application 734 in Karditsa County. Landslides 5:261-270.

736 Sharma S, Mahajan AK (2019) A comparative assessment of information value, frequency

737 ratio and analytical hierarchy process models for landslide susceptibility mapping of a 738 Himalayan watershed, India. Bull Eng Geol Environ 78(4):2431-2448. 
740 Turan, İ. D., Özkan, B., Türkeş, M., \& Dengiz, O. (2020). Landslide susceptibility mapping

741 for the Black Sea Region with spatial fuzzy multi-criteria decision analysis under semi-humid

742 and humid terrestrial ecosystems. Theoretical and Applied Climatology, 1-14.

743

744 Wang LJ, Guo M, Sawada K, Lin J, Zhang J (2015) Landslide susceptibility mapping in 745 Mizunami City, Japan: A comparison between logistic regression, bivariate statistical analysis 746 and multivariate adaptive regression spline models. Catena 135:271-282.

748 Xiao T, Yin K, Yao T, Liu S (2019) Spatial prediction of landslide susceptibility using GIS-

749 based statistical and machine learning models in Wanzhou County, Three Gorges Reservoir, 750 China. Acta Geochimica, 38:654-669.

752 Yan F, Zhang Q, Ye S, Ren B (2019) A novel hybrid approach for landslide susceptibility 753 mapping integrating analytical hierarchy process and normalized frequency ratio methods with 754 the cloud model. Geomorphology 327:170-187.

755

756 Youssef, A. M., Pradhan, B., Jebur, M. N., \& El-Harbi, H. M. (2015). Landslide susceptibility 757 mapping using ensemble bivariate and multivariate statistical models in Fayfa area, Saudi 758 Arabia. Environmen. Earth Sci. 73:3745-3761.

759

760 Zhang G, Cai Y, Zheng Z, Zhen J, Liu Y, Huang K (2016) Integration of the statistical index 761 method and the analytic hierarchy process technique for the assessment of landslide 762 susceptibility in Huizhou, China. Catena 142:233-244.

763

764 Zhu AX, Miao Y, Wang R, Zhu T, Deng Y, Liu J, Lin y, Qin CZ, Hong H (2018) A comparative 765 study of an expert knowledge-based model and two data-driven models for landslide 766 susceptibility mapping. Catena 166:317-327. 
Figures
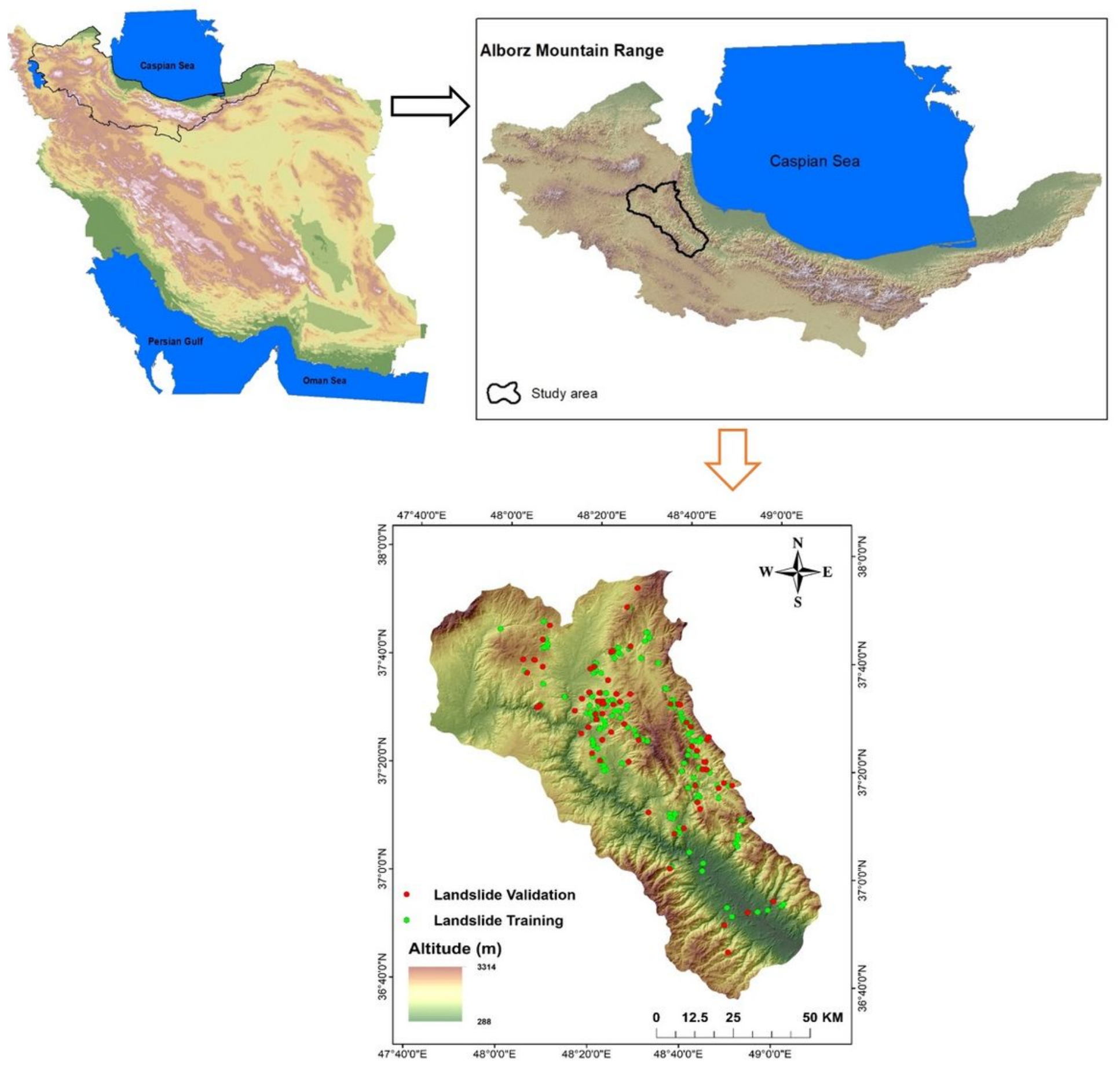

Figure 1

Location of the study area 

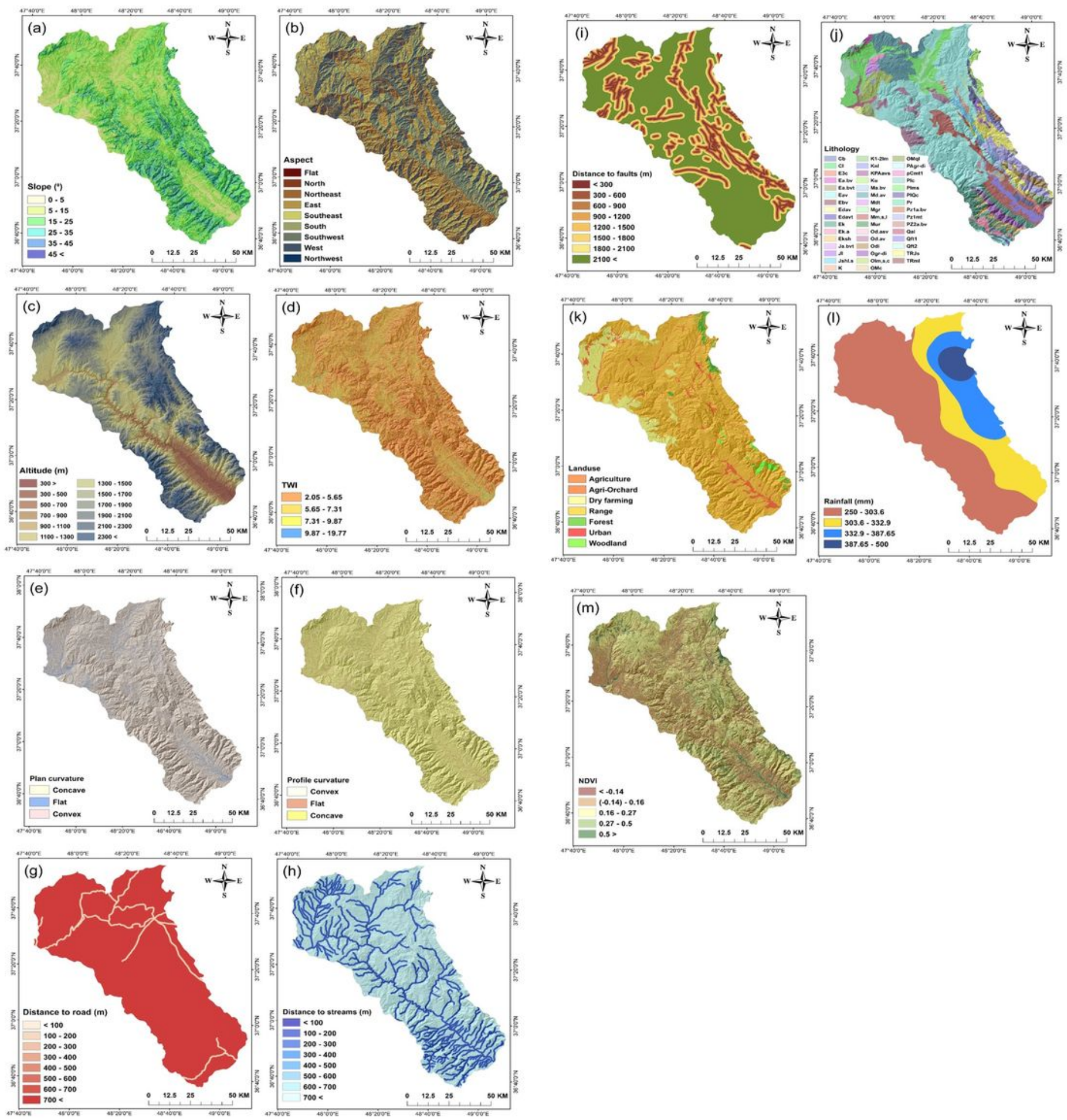

\section{Figure 2}

Produced conditioning factors of the study; a, slope angle; b, slope aspect; c, altitude; d, TWl; e, plan curvature; f, profile curvature; $g$, distance to roads; $h$, distance to streams; i, distance to faults; $j$, lithology; $k$, land use; l, rainfall; $m, N D V I$ 


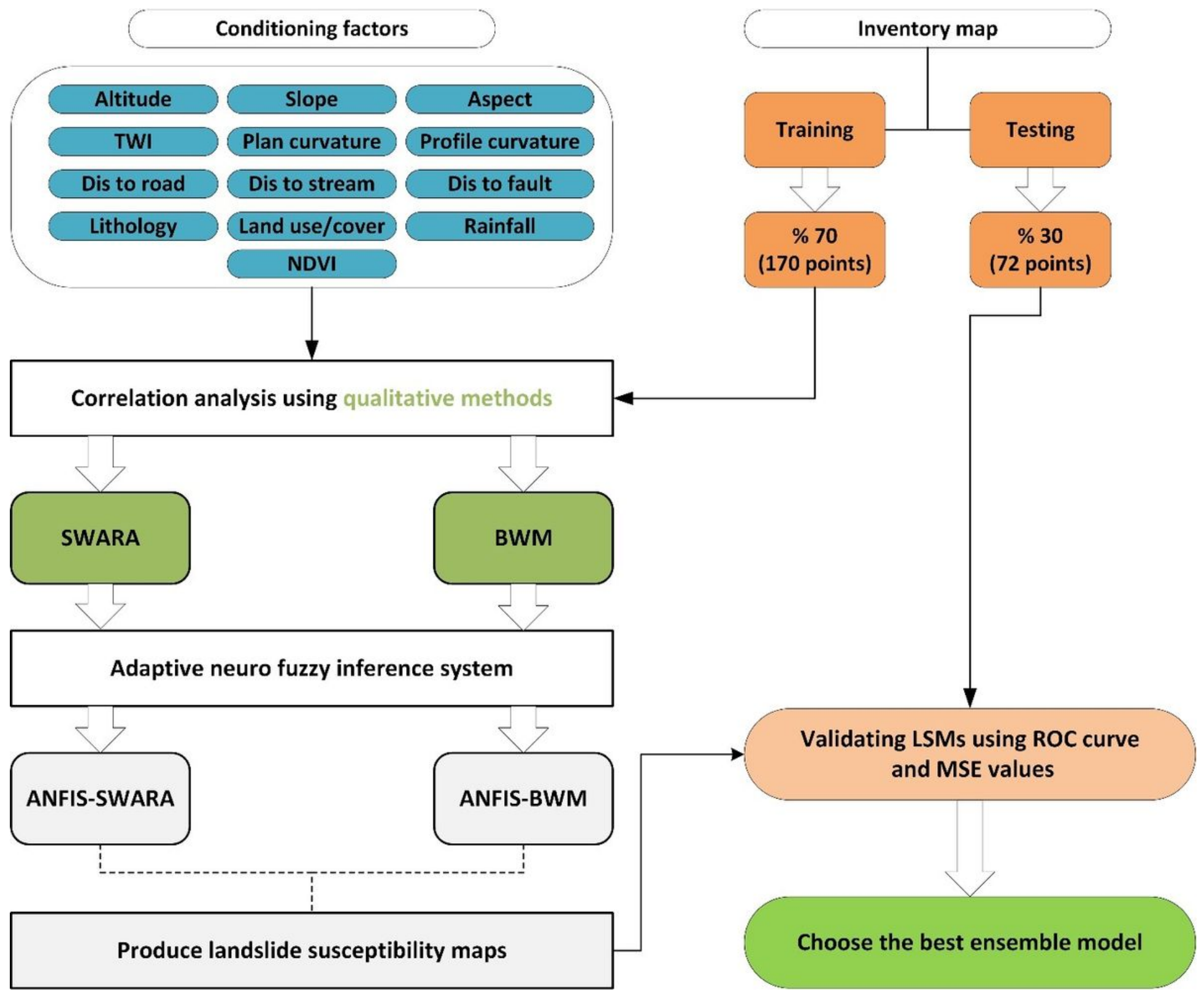

Figure 3

Flowchart of the study that showing all steps

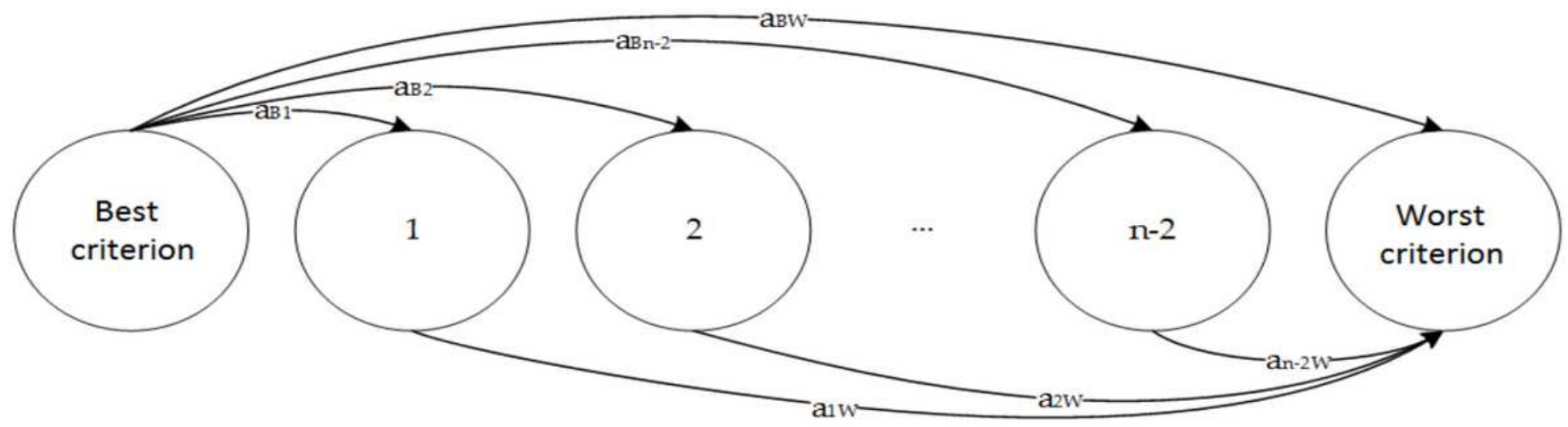

Figure 4 


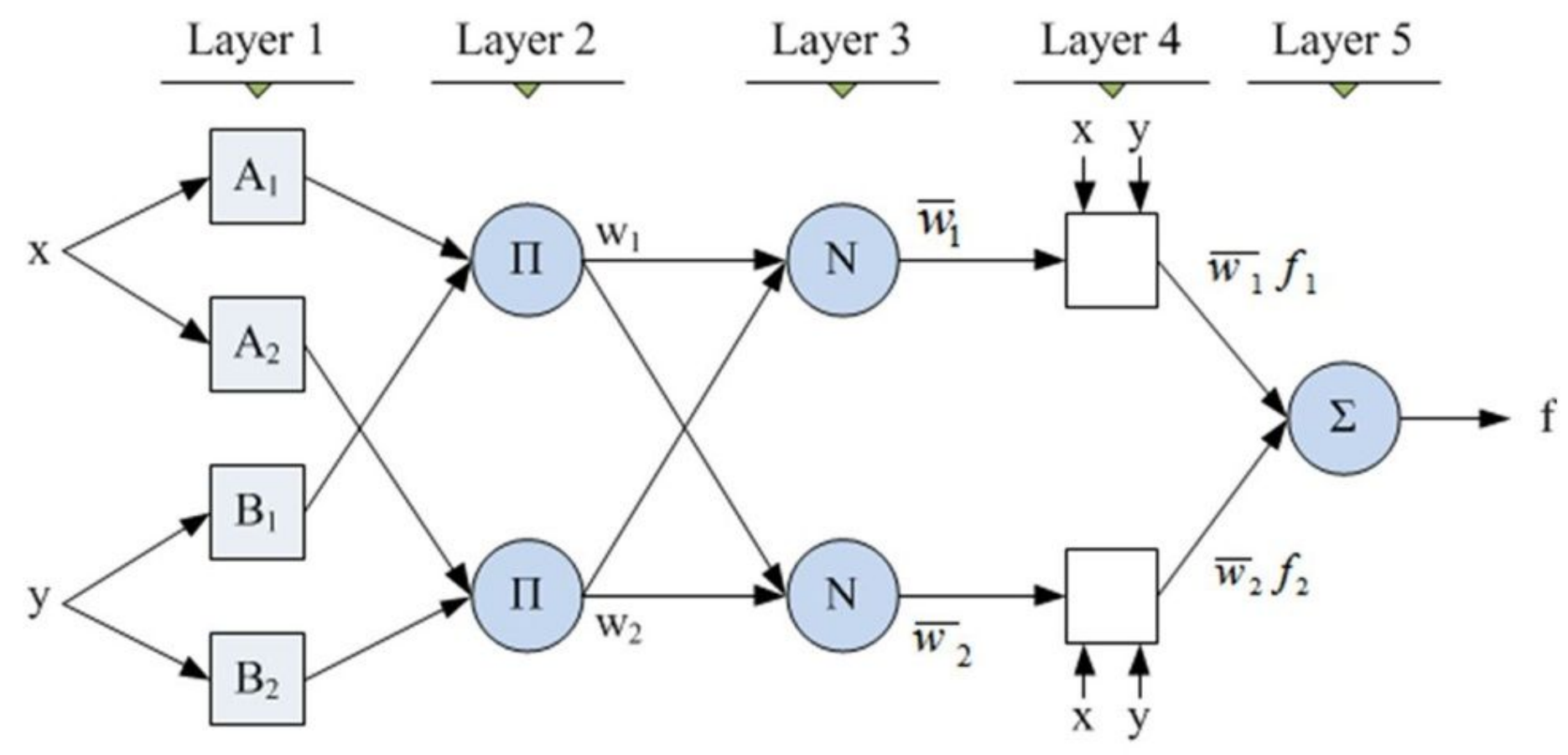

Figure 5

The structure of ANFIS model

ANFIS-
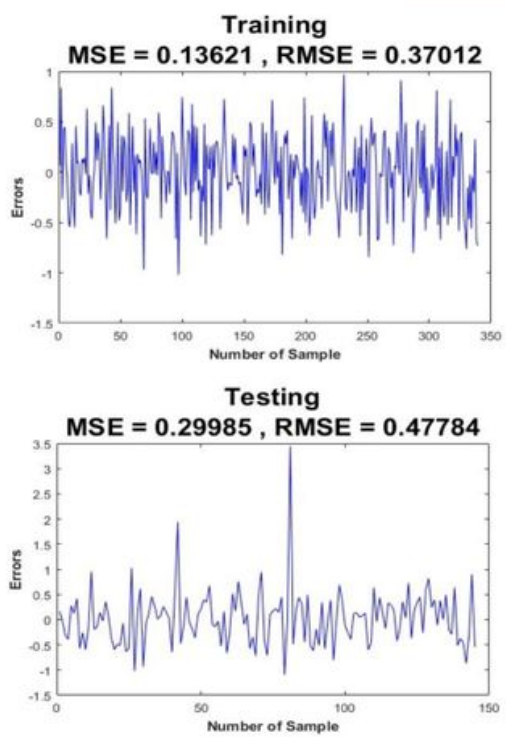
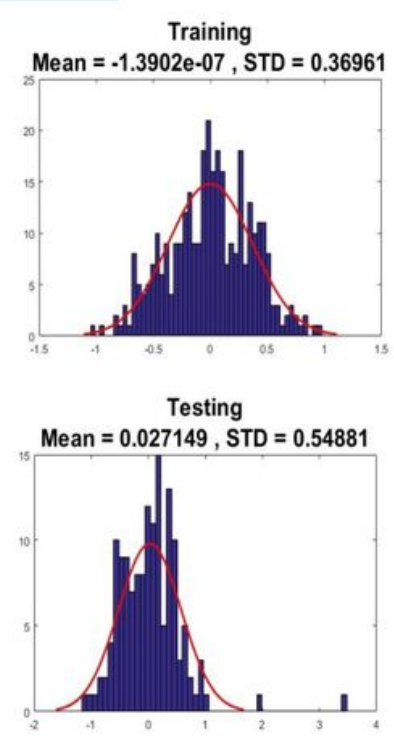

\section{ANFIS-BWM}
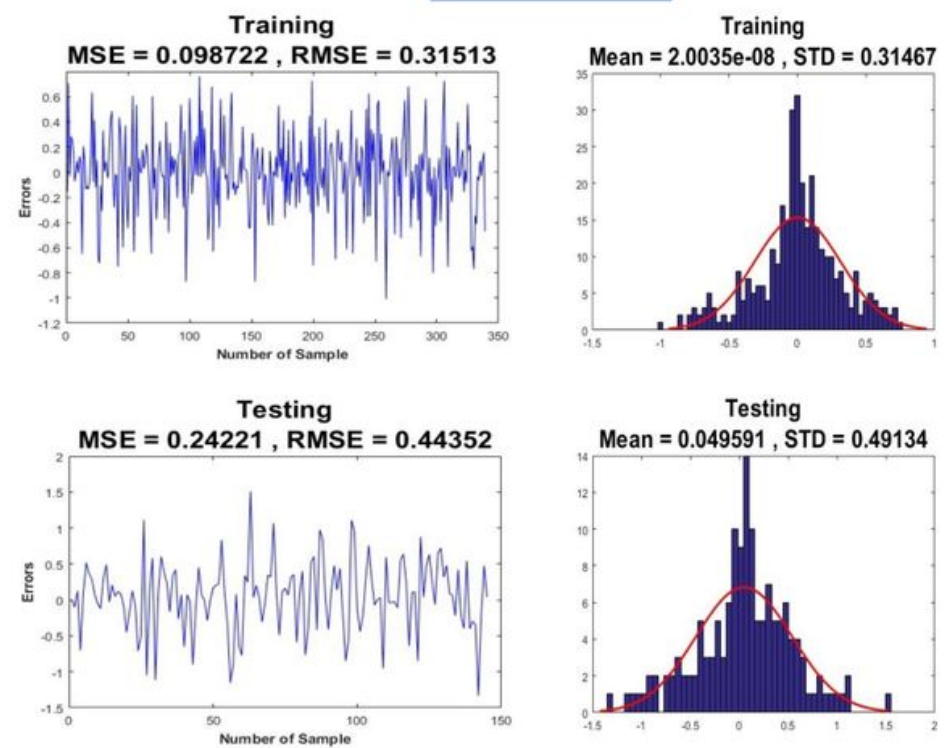

Figure 6

ANFIS-SWARA and ANFIS-BWM training and testing datasets a) MSE and RMSE value in the training phase; b) frequency errors in the training phase; c) MSE and RMSE value in the testing phase d) frequency errors in the testing phase 

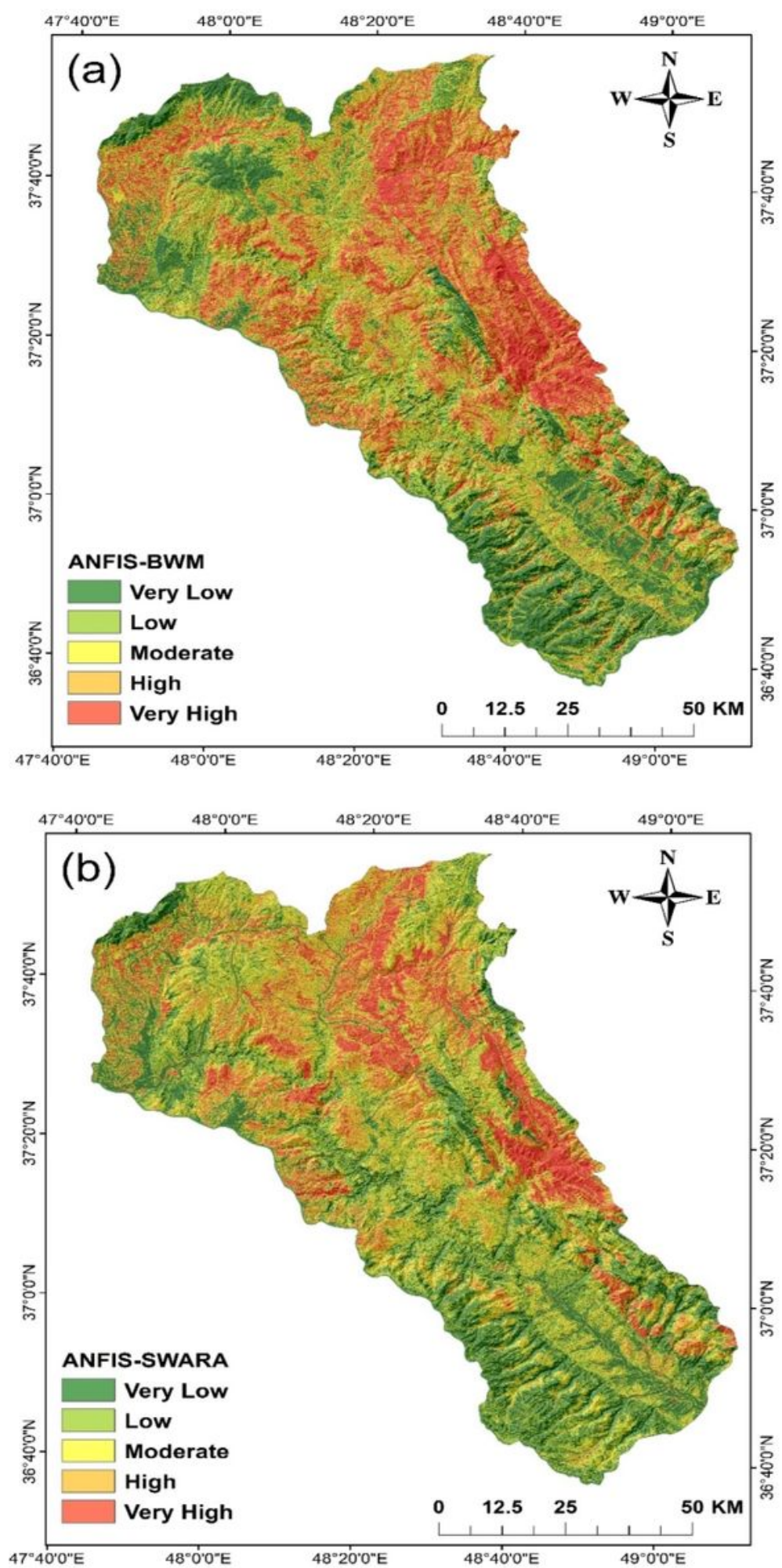

Figure 7

Landslide susceptibility map produced by ANFIS-BWM (a) and ANFIS-SWARA (b) models 


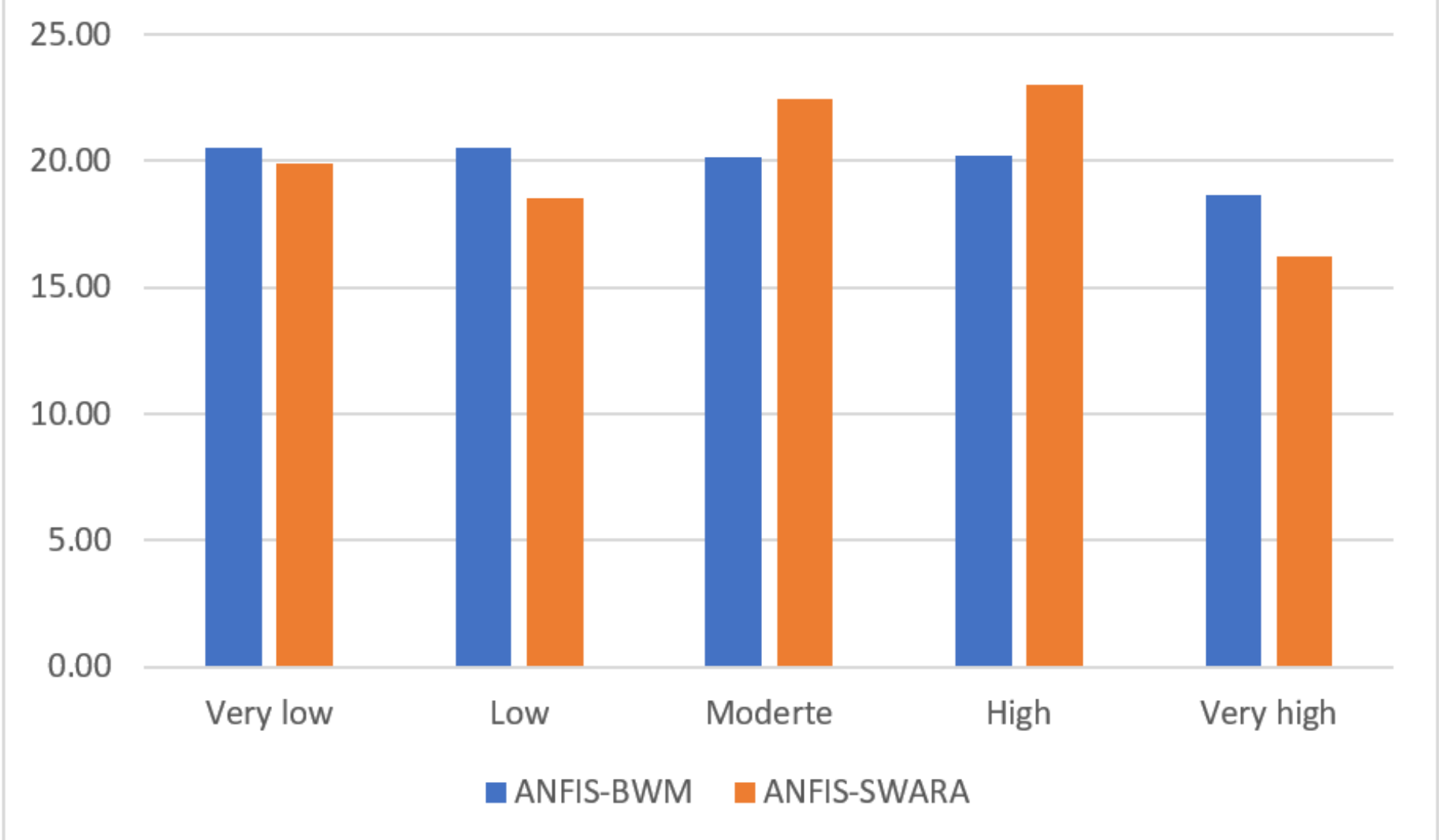

Figure 8

Percentages of landslide susceptibility classes 


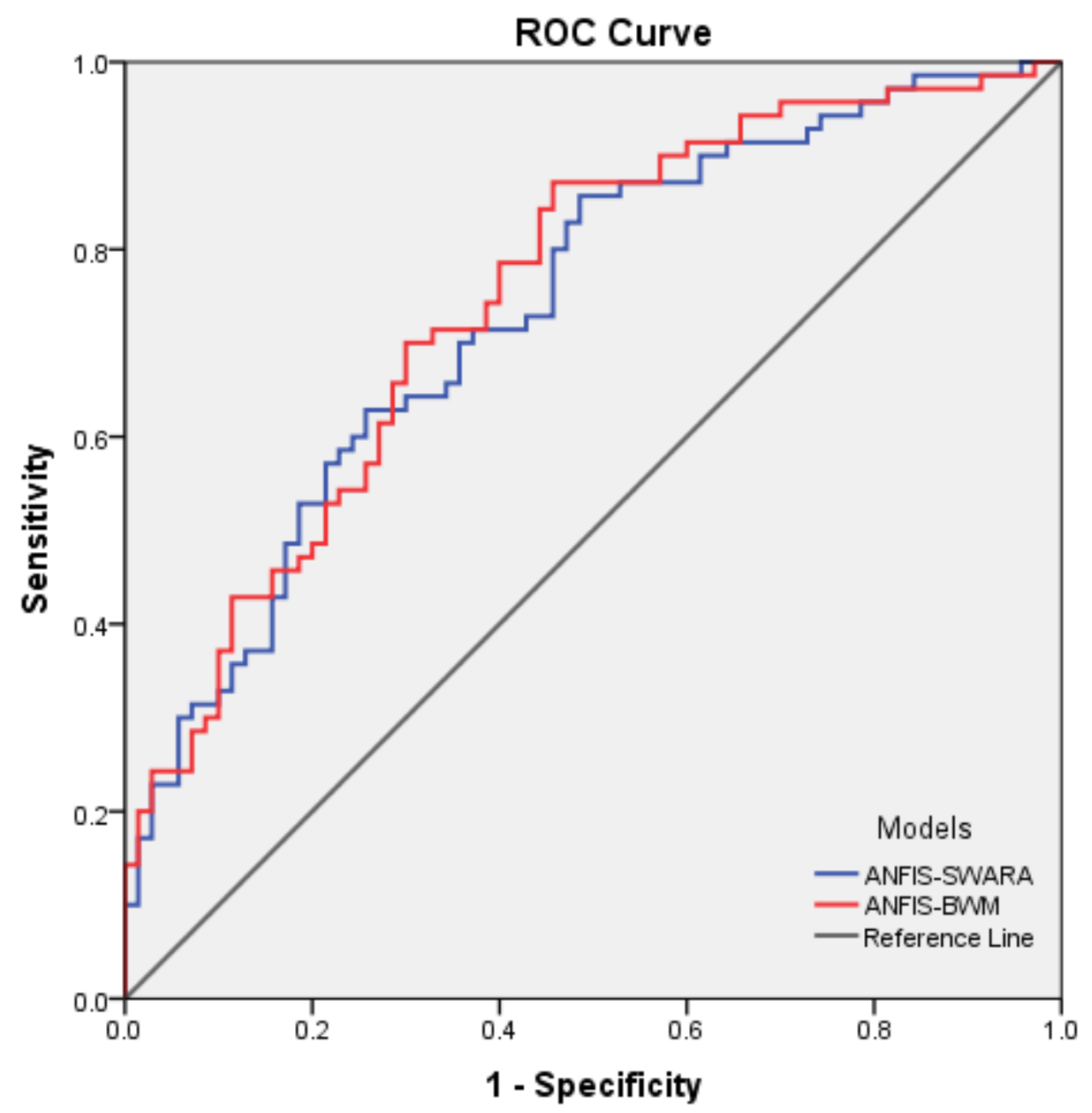

Figure 9

receiver operating characteristic curve for validation

\section{Supplementary Files}

This is a list of supplementary files associated with this preprint. Click to download.

- GraphicalAbstract.docx

- Highlight.docx 